\title{
POTENTIAL OF LOCAL CURRENCIES IN THE CZECH REPUBLIC: DSGE MODEL
}

\author{
KATEŘINA GAWTHORPE \\ University of Economics Prague, Faculty of Business Administration, \\ Department of Microeconomics, W. Churchill 4 Sq., Prague 3, Czech Republic \\ email: xzimk04@gmail.com
}

\begin{abstract}
The Czech Republic is an economy with one of the most municipalities per squared kilometer in Europe. The localization factor of individual municipalities causes their different reaction to exogenous shocks. The subsequent varying transmission of shocks into prices questions the convenience of the dominant position of the Czech currency for all regions. Instead, community currencies respect regional heterogeneity as well as endorse social values national currency is weak of targeting. Individuals, companies but also municipalities in other countries seem to realize these benefits of community currencies. Over four-thousands of community currencies operate worldwide. Spain belongs among one of the most recent member of such local-currency movement. High unemployment rate in Spain has motivated local activists to launch several time-banking schemes. These schemes multiplied into more than four hundred. Greece copied such effort to provide unemployed and impoverished individuals with additional means of exchange along with independence on scarce euro currency. Local currencies could help Czech Republic to respect regional discrepancies and allow local communities to be more flexible to transmission shocks and varying economic conditions. This study analyzes the benefits of such potential scenario with local currencies in the Czech Economy. The applied method represents an enhancement of the DSGE model as designed by the Ministry of Finance in the Czech Republic for local-currency variables. All set of monetary policy and fiscal policy shocks along with a shock into the local currency will allow to determine the potential importance of community currencies for the Czech Economy.
\end{abstract}

Key words: Local currencies, Alternative currencies, DSGE model, Czech Republic.

JEL Codes: E170, E510

\section{DOI: 10.15611/amse.2017.20.12}

\section{Introduction}

The alternative-currency movement modifies the world-wide monetary scene from a monotic circulation of legal tender currencies to the fascinating vibrant site hosting thousands of flourishing local-currency initiatives. Currently, over four thousand alternative currencies operate in various countries. (John Turmel list cited in [6] Gómez, 2010, p. 1672) Over six hundred local currencies promotes institutional trust in Japan. (Richey \& Ikeda, 2009) Alternative currencies Green Dollars have provided additional source of income to unemployed and under-employed individuals in New Zealand. (North, Money and Liberation) Redes de Trueque monetary system has reduced poverty during hyperinflation period in Argentina. (Gómez, 2010) Among other most famous examples belong over four-hundred time-banking schemes in the United States, Regiongeld in Germany, LETS systems in Great Britain, Switzerland's Wirtschaftsring and finally, the recent development of hundreds of 
local currencies in Greece and Spain. This numerous set of alternative currencies can be further classified into the group consisting of complementary currencies and those representing money substitute to a national currency.

Despite the diversity and the range of the currency initiatives, the spread of this movement into the Post-Communist bloc is less extensive. This vacuum is constituted partially by the historic period of communism when most of the social gathering was forbidden. This prohibition subsequently promoted lack of interest of individuals to participate in social movements. Unfortunately, even after the fall of Communistic regime, there have not been many cited cases of alternative currencies in the Eastern Europe. Among more famous currencies belong Kalaka an Kor in Hungary. Also in the Czech Republic, there exist only few examples of attempts to launch local currencies. The TNE in Sluknovsko is defined as a currency but its form of preservation glass diverts it from the foreign types of local currencies. Finally, the Czech legal system also does not support alternative currencies, any attempt to substitute Czech Crown outlawed.

The research in this paper questions the hostility of the Czech law system towards potential emergence of local currencies. By other words, it analyzes the potential impact of the community currencies namely of type LETS on the Czech economy.

The reason for the selection of LETS system as the subject of analysis is its worldwide dominance as one of the most common types of alternative currencies.

The applied method is an extended version of the Czech Ministry of Finance model "Hubert". The advantage of this DSGE model is its simulation character, which allows to test various scenario. The analyzed shocks in this paper consist of the monetary policy shock and fiscal policy shock along with the shock into an alternative currency.

The outline of the paper is as follows. The next part focuses on the mathematical extension of the original Hubert model. Subsequent section explains data for estimated parameters of the Czech economy. Finally, the discussion of the simulated results for individual shocks follows. Conclusion summing up the findings can be found at the end of this paper.

\section{Model}

This section of the paper presents the construction procedure of the model. The benchmark model is the Ministry of Finance model Hubert published by Aliyev et al. (2014). The main difference stems from the construction of nominal variables, which depends on the currency used for denominations. There are two currencies in this model, the national currency and the local currency. The local currency is assumed to be connected with adjustment costs. The presented model is non-linear as it incorporates non-linear network externality equation. Finally, the new model subject to simulation abstracts from government for purpose of simplification.

\subsection{Households}

The economy is populated by identical and infinitely - lived households indexed $j$. The households are heterogeneous, where only households of type "Savers" indexed by $R$ make decision based on optimization. "Spenders" consumption habits are given based on their budget constraint; their labor supply is inelastic. The budget constraint of Savers stays identical to the benchmark model.

The infinite stream of utility defines the preferences of Savers as: 


$$
E_{t} \sum_{t=0}^{\infty} \beta^{t} U_{t}=E_{t} \sum_{t=0}^{\infty} \beta^{t}\left[\begin{array}{c}
\frac{1}{1-\kappa}\left\{\frac{D_{j, t+n} \frac{\omega-1}{\omega}}{P_{t+n}^{D}}+\frac{M_{j, t+n}}{P_{t+n}}{ }^{\frac{\omega-1}{\omega}}\right\}^{\frac{\omega(1-\kappa)}{\omega-1}} \\
+\log \left(C_{j, t+n}^{R}-H_{j, t+n}\right)-\frac{\left(N_{j, t+n}^{R}\right)^{1+\psi^{N}}}{1+\psi^{N}}
\end{array}\right]
$$

where $0<\beta<1$ is a subjective intertemporal discount factor and $\beta=\frac{1}{1+\bar{\omega}}$. The parameter $\bar{\omega}$ from the previous equation represents the subjective rate of time preference. The variable $H_{j, t}=h_{r} C_{j, t-1}$ in the utility function stands for the external habit formation. Consumption variable then represents a basket of heterogeneous final products defined in the line with the study of Dixit and Stiglitz (1977). $N_{j, t}^{R}$ labels labor supply and parameter $\psi^{N}$ the real wage elasticity of the labor supply. These households also decide which currency $M_{j, t}$ or $D_{j, t}$ they want to demand. The first currency is legal tender and the second one characterizes local currency. Both currencies are in the real form. The parameter $\omega$ symbolizes the degree of substitution between the currencies.

Households of type Savers need to respect the budget constraint:

$$
\begin{aligned}
\left(1+\tau_{t}^{c}\right) P_{t}^{C} C_{j, t}^{R} & +P_{t}^{I} I_{j, t}+P_{t} a\left(u_{j, t}\right) K_{j, t}^{s}+\frac{1}{R_{t}} B_{j, t+1}+\frac{1}{R_{t}^{*}+\varsigma_{t}} S_{t} B_{j, t+1}^{*}+F_{j, t}\left(1+A C_{t}^{l}\right) \\
& =B_{j, t}+S_{t} B_{j, t}^{*}+\left(1-\tau_{t}^{k}\right)\left[R_{t}^{k} u_{j, t} K_{j, t}^{s}+Q_{t}\right]+\left(1-\tau_{t}^{w}\right) W_{t} N_{j, t}^{R}+F_{t-1}
\end{aligned}
$$

The labels and intuition behind individual variables in the budget constraint stays alike the benchmark model. (See Aliyev et al., 2014) The only difference concerns the introduction of money variable $F_{j, t}$. This variable is a composite money variable, which consists of the local currency and the legal tender, therefore: $\left.F_{j, t}=\left\{\frac{D_{j, t+n} \frac{\omega-1}{P_{t+n}^{D}}}{{ }^{D}}+\frac{M_{j, t+n}}{P_{t+n}}\right\}^{\frac{\omega-1}{\omega}}\right\}^{\frac{\omega}{\omega-1}}$. To follow the similar introduction into the model as the consumption aggregate, the money variable enters the budget constraint in nominal form as: $F_{j, t}=M_{j, t}+D_{j, t}$.

The inclusion of the adjustment costs variable $A C_{t}^{l}$ corresponds to the intuition of higher cumbersomeness of carrying transactions in an economy with multiple currencies.

$$
A C_{t}^{l}(j)=\left[\frac{\Psi_{a}}{2}\left(\frac{\pi_{t}(j)}{\theta_{t}(j)}\right)^{2}\right] Y_{t}
$$

This definition of adjustment costs follows the paper of Falagiarda \& Marzo (2012), which also applies quadratic adjustment costs although for bonds. Steady-state value for the adjustment costs is assumed to be non-zero, generating a non-zero demand for currencies in the long - run.

These costs include information costs and costs for carrying transactions in scenario with local currencies. One can also interpret these costs as switching costs, costs of switching the established currency for a new less common one. Individuals suffer costs from attempts to use not yet well-established currency for mediating exchanges. Higher adjustment costs pertain then to a less common currency where individuals suffer from the difficulties stemming from its lower acceptance. Inflation rate negatively affects the adjustment costs. This link 
corresponds to my previous study Gawthorpe (2015). Demand for a local currency increases when the national currency faces inflationary pressures.

In contrast to the study of Falagiarda \& Marzo (2012), the adjustment costs variable in the presented model differs by the inclusion of network externality.

$$
\theta_{t}(j)=\frac{F_{t}(j)}{F_{t}(j)-D_{t}(j)}
$$

The network externality measures the degree of willingness of individuals to accept a currency given its current membership. This variable ranges between zero and one. Relative increase in the circulation of the currency rises network externality, network of individuals using the currency, which reduces the adjustment costs. For example, in case of the legal tender currency where its size of usage approximates that of total money in circulation, the network externality variable equals one. By other words, the more individuals hold onto the currency in respect to the total amount of money in circulation, the less burden needs to be overcome to make sellers/buyers accept it in payment. The network-externality variable enters the model in non-linearized form such as the externality effect in economy is assumed to be exponential.

The optimality conditions for the households' optimization problem stays identical to the original Hubert model except for the money demand equation for the legal tender:

$$
\frac{\mathrm{M}_{\mathrm{t}}}{\mathrm{P}_{\mathrm{t}}}=\left(\frac{\beta\left(1+\mathrm{i}_{\mathrm{t}}^{\mathrm{M}}\right)}{\left(1+\mathrm{A} \mathrm{C}_{\mathrm{t}}^{\mathrm{M}}(\mathrm{i})\right)\left(1+\mathrm{i}_{\mathrm{t}}^{\mathrm{M}}\right) \beta-1}\right)^{\omega}\left(\mathrm{C}_{\mathrm{j}, \mathrm{t}}^{\mathrm{R}}-\mathrm{h}_{\mathrm{r}} \mathrm{C}_{\mathrm{j}, \mathrm{t}-1}^{\mathrm{R}}\right)^{\omega}\left(1+\tau_{\mathrm{t}}^{\mathrm{c}}\right)^{\omega}\left(\mathrm{P}_{\mathrm{t}}^{\mathrm{c}}\right)^{\omega}\left(\mathrm{F}_{\mathrm{t}}\right)^{\frac{1-\kappa \omega}{1-\kappa}}
$$

and the demand for the local currency:

$$
\frac{D_{t}}{P_{t}^{D}}=\left(\frac{\beta\left(1+i_{t}^{D}\right)}{\left(1+A_{t}^{D}(i)\right)\left(1+i_{t}^{D}\right) \beta-1}\right)^{\omega}\left(C_{j, t}^{R}-h_{r} C_{j, t}^{R}\right)^{\omega}\left(1+\tau_{t}^{c}\right)^{\omega}\left(P_{t}^{c}\right)^{\omega}\left(F_{t}\right)^{\frac{1-\kappa \omega}{1-\kappa}}
$$

where

$$
\frac{F_{t}}{P_{t}}=\left(\frac{\beta\left(1+i_{t}\right)}{\left(1+i_{t}\right) \beta-1}\right)^{\kappa}\left(C_{j, t}^{R}-h_{r} C_{j, t-1}^{R}\right)^{\kappa}\left(1+\tau_{t}^{c}\right)^{\kappa}\left(P_{t}^{c}\right)^{\kappa}
$$

In correspondence to the original model, each household $j$ of both types spenders and savers is a monopoly supplier of differentiated labor N. (See Aliyev et al., 2014)

\subsection{Firms}

The firm sector is also subject to modification. Alike the original version, the market is characterized by monopolistic competition, which leads to rigidities in price-setting. Only 1- $\rho$ fraction of firms adjust their prices in period t. Before firms make decision over the size of their prices for the next period, they must decide about price denomination for their goods.

This currency decision depends upon the maximization of profit:

$$
\Pi_{\mathrm{t}}(\mathrm{i})=\mathrm{P}_{\mathrm{t}}(\mathrm{i}) \mathrm{Y}_{\mathrm{t}}(\mathrm{i})-\mathrm{TC}_{\mathrm{t}}(\mathrm{i})
$$

with respect to the currency index:

$$
P_{t}(i)=\left(\int_{0}^{1} P_{t}(i, j)^{1-\frac{1}{\vartheta}} d j\right)^{\frac{\vartheta}{9-1}}
$$


and the total price for goods of a firm:

$$
\mathrm{TC}_{\mathrm{t}+\mathrm{k}}(\mathrm{i})=\frac{\omega_{\mathrm{t}+\mathrm{k}}(\mathrm{i})}{(1-\alpha) \mathrm{z}_{\mathrm{t}+\mathrm{k}}^{1-\alpha}}\left(\frac{\mathrm{ir}_{\mathrm{t}+\mathrm{k}}(\mathrm{i})(1-\alpha)}{\omega_{\mathrm{t}+\mathrm{k}}(\mathrm{i}) \alpha}\right)^{\alpha} \mathrm{Y}_{\mathrm{t}+\mathrm{k}}(\mathrm{i})
$$

In the above equation $\omega_{t}(i)$ illustrates nominal wage and $\mathrm{ir}_{\mathrm{t}}(\mathrm{i})$ nominal interest rate defined as:

$$
\begin{aligned}
& \omega_{t}(i)=P_{t}(i) w_{t}(i)=\int_{0}^{1} E_{t}(j) P_{t}(i, j) w_{t}(i, j) d j \\
& i r_{t}(i)=P_{t}(i) r_{t}(i)=\int_{0}^{1} E_{t}(j) P_{t}(i, j) r_{t}(i, j) d j
\end{aligned}
$$

The above identities express equality between the variable in nominal terms and real variable multiplied by price in the currency $j$ and transformed into the legal tender with a help of nominal exchange rate.

The maximization of the profit function (22) with respect to the above-derived identities results in demand for the currency " $j$ " by a firm " $i$ ":

$$
P_{t}(i, j)=\left((1-\alpha) \frac{w_{t}(i, j)}{\omega_{t}(i)}+\alpha \frac{r_{t}(i, j)}{i r_{t}(i)}\right)^{-\vartheta} P_{t}(i)^{1+\vartheta}
$$

This last equation follows the intuition of higher relative prices denominated in more demanded currency. Employees are in turn willing to accept lower wages in such preferable currency. The prices in the local currency and legal tender are subject to aggregation in the following manner:

$$
P_{t}=s_{d s} P_{t}(j)+\left(1-s_{d s}\right) P_{t}(m)
$$

Substitution of the equation (4) for prices in the isoelastic demand function allows to compute the New-Keynesian Phillips curve as:

$$
\begin{aligned}
& \widehat{\mathrm{P}}_{\mathrm{t}}^{*}(\mathrm{i}, \mathrm{j})=\frac{\rho}{1+\beta \rho^{2} \mathrm{u}_{\mathrm{z}}} \widehat{\mathrm{P}}_{\mathrm{t}-1}(\mathrm{i}, \mathrm{j})+\frac{\beta \rho \mathrm{u}_{\mathrm{z}}}{1+\beta \rho^{2} \mathrm{u}_{\mathrm{z}}} \widehat{\mathrm{P}}_{\mathrm{t}+1}(\mathrm{i}, \mathrm{j})-\frac{(1-\rho) \vartheta \beta \rho \mathrm{u}_{\mathrm{z}}}{\left(1+\beta \rho^{2} \mathrm{u}_{\mathrm{z}}\right)^{\mathrm{T}}}\left[(1-\alpha)\left(\Pi_{\mathrm{t}}^{\mathrm{w}}(\mathrm{i}, \mathrm{j})-\Pi_{\mathrm{t}}^{\mathrm{w}}(\mathrm{i})\right)+\right. \\
& \left.\alpha\left(\Pi_{\mathrm{t}}^{\mathrm{r}}(\mathrm{i}, \mathrm{j})-\Pi_{\mathrm{t}}^{\mathrm{r}}(\mathrm{i})\right)\right]-\frac{(1-\rho) \vartheta}{\left(1+\beta \rho^{2} \mathrm{u}_{\mathrm{z}}\right) \mathrm{T}}\left(1-\frac{\beta \rho \mathrm{u}_{\mathrm{z}}}{1+\beta \rho^{2} \mathrm{u}_{\mathrm{z}}}\right)\left[(1-\alpha)\left(\widetilde{\mathrm{w}}_{\mathrm{t}}(\mathrm{i}, \mathrm{j})-\widetilde{\mathrm{w}}_{\mathrm{t}}(\mathrm{i})\right)+\alpha \frac{\overline{\mathrm{r}}(\mathrm{i}, \mathrm{j})}{\mathrm{r}(\mathrm{i})}\left(\widetilde{\mathrm{r}}_{\mathrm{t}}(\mathrm{i}, \mathrm{j})-\right.\right. \\
& \left.\left.\widetilde{\mathrm{r}}_{\mathrm{t}}(\mathrm{i})\right)\right]+\frac{(1-\rho)\left(1-\beta \rho \mathrm{u}_{\mathrm{z}}\right)}{1+\beta \rho^{2} \mathrm{u}_{\mathrm{z}}} \widehat{\mathrm{MC}}_{\mathrm{t}}(\mathrm{i})
\end{aligned}
$$

\subsection{Labor market}

The existence of the wage-stickiness on the labor market is modelled in a similar way as the price stickiness. The currency selection for wage denomination again precedes the decision over the size of wages.

For the wage-selection process, firms take into consideration the preferences of households over wage denomination. The size of wage then depends upon the optimization problem of households, which maximize their utility function subject to the intertemporal budget constraint. The currency index in the optimization problem for this section is further disaggregated as:

$$
E_{t}(j) \frac{f_{t}(j)}{P_{t}^{F}(j)}=\left(\int_{0}^{1} \xi_{t}(k) \frac{f_{t}(j)}{P_{t}(j)} \frac{c-1}{c} d k\right)^{\frac{c}{c-1}}
$$


The utility function is then subject to disaggregation to consider this index. Individual currencies in the composite index $\mathrm{f}_{\mathrm{t}}$ are obtained from various sources. The

parameter $\xi_{t}(k)$ enables to differentiate between various sources " $\mathrm{k}$ " of received money. By other words, when an individual holds money, part of it initiates as wages, the other part comes from other origins. The share of money obtained in the form of wage will be labeled $\varpi_{t}(M)$ or $\varpi_{t}(d)$ depending on the type of currency denomination of wages.

The disaggregated currency index enters the budget constraint in the form:

$$
\begin{aligned}
\mathrm{w}_{\mathrm{t}}^{\mathrm{d}} \mathrm{L}_{\mathrm{t}} & =\varpi_{\mathrm{t}}(\mathrm{D}) \frac{\mathrm{F}_{\mathrm{t}}}{\mathrm{P}_{\mathrm{t}}} \\
\mathrm{w}_{\mathrm{t}}^{\mathrm{M}} \mathrm{L}_{\mathrm{t}} & =\varpi_{\mathrm{t}}(\mathrm{M}) \frac{\mathrm{F}_{\mathrm{t}}}{\mathrm{P}_{\mathrm{t}}}
\end{aligned}
$$

Notice the similarity of the disaggregation procedure to the Dixit-Stiglitz index.

Derivation of the utility function given the budget constraint subject to the share of currency $\mathrm{j}$ obtained as wages $\varpi_{\mathrm{t}}(\mathrm{j})$ results in the following equation:

$$
\frac{w_{t}^{d}}{w_{t}^{M}}=\left(\frac{b}{1-b} \frac{M_{t}^{\frac{1}{\omega}}}{D_{t}^{\frac{1}{\omega}}}\right)^{c}
$$

with a log-linearized form:

$$
w_{t}(d)-w_{t}(m)=\frac{c}{\omega} M_{t}-\frac{c}{\omega} D_{t}
$$

Individual households are therefore willing to accept lower wages in the preferable currency. This intuition corresponds to the one in the price-setting section.

For the reason of aggregation, the total wage equals the sum of the shares of wages in the alternative currency multiplied by the amount of the currency:

$$
w_{t}=s_{d s} w_{t}(d)+\left(1-s_{d s}\right) w_{t}(m)
$$

Maximization of the utility function (1) rewritten for time $\mathrm{t}+\mathrm{k}$ for a household which sets its wage in period $t$ :

$$
E_{t}\left\{\sum_{k=0}^{\infty}\left(\beta \rho_{w}\right)^{k} U\left(C_{t+k / t}, N_{t+k / t}, M_{t+k / t}, S C_{t+k / t}\right)\right\}
$$

subject to the budget constraint, which remains identical to the original one for time $\mathrm{t}+\mathrm{k}$ for $\mathrm{k}=0,1,2 \ldots$ with consideration of sticky wages and the constraint

$$
L_{t+k / t}=\left(\frac{w_{t}^{d *}(j) \frac{D_{t} \frac{c}{\omega}}{\frac{c}{\omega}}}{M_{t}^{\frac{c}{\omega}}}\right)^{-\theta_{w}} L_{t+k}
$$

Inclusion of the result of simple derivation into the wage aggregation equation, which stays alike the original Hubert version: 


$$
\left(W_{t}^{j}\right)^{1-\theta_{w}}=\alpha_{R}\left[\epsilon_{w}\left(W_{t-1}^{j}\right)^{1-\theta_{w}}+\left(1-\epsilon_{w}\right)\left(W_{t}^{j *}\right)^{1-\theta_{w}}\right]+\left(1-\alpha_{R}\right)\left(W_{t-1}^{j}\right)^{1-\theta_{w}}
$$

leads to the final stationary wage equation for the model:

$$
p_{w w} \widehat{W}_{t}^{j *}=\beta \epsilon_{w} \widehat{W}_{t+1}^{j}+p_{w i} \widehat{W}_{t-1}^{j}+p_{w l} E\left(\hat{L}_{t}^{j}\right)-p_{w n} \widehat{N}_{t}^{j}+p_{w z}\left(\frac{c}{\omega}\left(M_{t}-D_{t}\right)\right)
$$

where

$$
\begin{gathered}
p_{w w}=\left\{1+\left[1-\alpha_{R}\left(1-\epsilon_{w}\right)\right] \beta \epsilon_{w}+(1\right. \\
\left.\left.-\beta \epsilon_{w}\right)\left[\Psi_{N} \theta^{w}-\alpha_{R}\left(1-\epsilon_{w}\right)\left(\frac{\theta^{w}}{\theta^{w}-1}\right)\left(\psi_{N} \theta^{w}+1\right)\right]\right\} \\
p_{w i}=\left\{\left[1-\alpha_{R}\left(1-\epsilon_{w}\right)\right]+\left[1+\Psi_{N} \theta^{w}\left(1-\beta \epsilon_{w}\right)\right]\right\} \\
p_{w l}=\alpha_{R}\left(1-\epsilon_{w}\right)\left(1-\beta \epsilon_{w}\right) \Psi^{N} \\
p_{w n}=\left(1-\epsilon_{w}\right)\left(1-\beta \epsilon_{w}\right) \frac{\bar{N}}{\bar{N}^{R}} \\
p_{w z}=\left(1-\epsilon_{w}\right)\left(1-\beta \epsilon_{w}\right)
\end{gathered}
$$

This outcome corresponds to the preceding section as well as to the result of the firm sector. The more is the alternative currency demanded in respect to the legal tender, the lower relative wages denominated in the alternative currency employees demand.

The foreign sector mimics the original model. In regards to individual shocks, all of them represent autoregressive processes AR(1) with the error term being zero mean white noise process. The shocks of interest consist of the monetary policy shock, shock into the income tax, shock into the VAT tax and shock into the demand for the local currency.

\section{Model Estimation}

The simulation of the above derived model is based on the parameter estimates from the Table 1. The values of all the parameters with the exception of those concerning currencies stay identical to the benchmark model Aliyev et al. (2014). Aliyev et al. (2014) estimate the parameters on the data from the Ministry of Finance database with quarterly frequency. Readers interested in understanding in detail the estimation and calibration procedure are referred to their study.

The sparse empirical literature on the topic of multiple currencies disables regression analysis of the values for the currency parameters. For that reason, the parameter values are subject to calibration. Namely, such parameters are $\omega$ labeling the elasticity of substitution between the two types of currencies, parameter $v$ and $c$ which concerns the degree of substitutability for price and wage denominations respectively.

The low value of 0.01 for these parameters attempts to express the complementary character of the most current local currencies such as those of type LETS or Time-banks. Finally, the parameter $s_{\mathrm{ds}}$ stands for the share of individual currencies in the total money aggregate. The share is assumed to be 0.01 . 
The outcome of the model is robust to the parameters' alternations, what differs is the sensitivity of reaction of the aggregate variables not the direction of the response to individual shocks. The introduction of these values illustrates the currently relatively low percentage local currencies tend to have in an economy.

The log-linearized equations of the model except for the network externality, where the necessity of its exponential shape requires non-linear nature, are then simulated in Matlab.

\section{Results}

The Figures 1 till 4 present the outcome of the simulation for the studied shocks. The output of the monetary policy shock with realization of size 1 is visible on the Figure 1 . The direction of response for individual variables assimilates the original Hubert model from Aliyev et al. (2014). Restrictive monetary policy formalized by the increase of interest rate has negative impact on output, consumption, investment as well as export. The interest rate growth causes appreciation of the real exchange rate defined by uncovered interest rate parity. Import then rises in response to now relatively cheaper foreign currency. Deflationary tendencies for domestic prices are also well known reaction to the restrictive monetary policy. The advantage of the existence of a local currency in such scenario is the option for agents to switch to the relatively more abundant local currency. The display of the increase in relative demand for local currency in respect to legal tender is available on the subplot labeled as MD difference. In the situation where multiple currencies circulate, individuals substitute the shortage of the national currency by the increase in demand for the local currency. The plot with the title "MD diff", which denotes the difference in demand between the local currency and the legal tender reflects such situation. Higher demand for the local currency enables employers to pay relatively lower wages while charging relatively higher prices for their products as the local currency is now more demanded medium of exchange. Nominal interest rate for the local currency drops as visible on the plots as the growth of demand for the local currency means lower risk for lenders. Altogether, the decrease of production costs along with the raise of revenue in local currency helps to reduce the negative effect of the monetary policy shock on the economy. Local economy becomes more resilient towards monetary policy shock for the national or international currency.

The next simulated shock is the shock into the VAT tax rate on the Figure 2 followed by the shock into the income tax on the Figure 3. The reaction of the variables to either of these shocks also assimilates the original version of the model. Both shocks have negative impact on output, consumption, export but also import as the interest rate drops as well. The variable Investment on the other hand positively reacts to lower interest rate. Demand for local currency but also legal tender decreases with lower consumption. The alternation of the tax rates then affects both types of these currencies uniformly.

Perhaps the most interesting shock is the shock into the demand for a local currency from the Figure 4. This shock yields expansionary effect on output, consumption, export and import. The overall low responsiveness of individual variables towards the local-currency shock originates in the low value of the parameter $s_{\mathrm{ds}}$. The higher is the share of the local currency in the money aggregate the more sensitive would be the variables towards this shock.

The explanation behind the chain of reaction towards the shock starts with the demand for the local currency. Higher demand for the local currency allows producers to ask for higher prices for their products while paying lower wages. The growth of prices along with reduction of wages improves the financial situation of enterprises. Profit booms and in turn so does production. Expansionary effect coped with relative drop of wages in the local currency subsequently booms labor demand and by doing so helps to lessen unemployment. Both facts 
are known feature of local currencies abroad. In sum, Figure 4 indicates beneficial outcome of the pure growth of demand for a local currency in terms of increases of economic product.

The result is though not unambiguous. Inflationary pressures result as side effect of such economic boom. Lower demand for legal tender is also a negative outcome of this multiplecurrency scenario. Although the local currency complements the national one, individuals still decide in which one to carry their transaction and by doing so diminish demand for the legal tender while opting for the local currency. Next, the economic prosperity and inflationary pressures are coped with interest rate growth. Increase in costs for loans in the national currency result in lower investment. The final negative consequence of this local-currency demand shock is the appreciation of currency. To reflect the reality, the model assumes independence of import and export equations on the local currency as these currencies are commonly designed not to be used nor demanded outside the community. Nevertheless, the exchange rate is affected by the nominal interest rate. While the appreciation appears very low on the Figure 4, it still leads to the drop of net export which subsequently hampers the growth of economic product.

Altogether, the circulation of the alternative currency is beneficial in terms of higher resilience for the community thanks to the option to switch to another currency during periods of the negative exogenous shock into the demand for one currency such as the monetary policy shock. The growth of demand for the local currency itself positively affect economic product measured by GDP although inflation might increase as the consequence.

\section{Discussion}

The contemporaneous proliferation of local currency movement motivates this research to study potential impact of the alternative currencies of type LETS on the Czech economy. As already mentioned there have been altogether only few attempts in the Czech Republic to launch a local-currency project. On the other hand, the Czech economy exhibits favorable conditions for local-currency initiatives. The generous number of the networks of small municipalities creates positive environment for endorsing localization and resilience. Many of the Czech municipalities have had experience with agriculture, localization could improve their self-sufficiency. The lower dependence on exogenous shocks could also be beneficial for the local regions.

But local currencies are promising also for other than economic reasons. They are known to promote social capital such as Talentum in Hungary in the 1990th. They help unemployed but also marginalized groups to get involved in a society. The aid for poor incentive is well documented for the currency Redes de Trueque in Argentina, the Green Dollars helped underemployed individuals to additional income in New Zealand or the Time Banks in the United States have helped retired, disabled or other individuals in the outskirt of the society to get more involved in a community. The lack of social engagement is especially troubling the post-communist block of countries.

Finally, the Figure 4 in this paper supports the positive potential impact of demand for a local-currency on the economic activity in the Czech Republic. The growth of production due to the growth of liquidity from the introduction of new relatively cheap currency helps local businesses to improve their financial situation. Individuals then benefit from growth of labor demand as the production growth while the wages denominated in the local currencies tend to drop. The model in this study then offers additional tool for simulating potential impactevaluation of local currencies.

Other authors support the positive outcome for local-currency scenario as well. For example, Colacelli and Blackburn (2009) discover a positive effect of an acceptance of 
alternative currencies on economic activity in Argentina with a use of propensity matching method. The game theory model constructed by Jayaraman and Oak (2002, Local currency as a development strategy) finds alternative currencies as a positive signal raising productivity of local companies in developing countries.

\section{Conclusion}

At the first sight, local currency movement appears ubiquitous. This grassroots movement thrives in many parts of the world. Nevertheless, the Czech Republic seems to resist to such currency trend. This article attempts to analyze the potential importance of local currencies for the Czech economy with help of the DSGE model. The model is an extended version of the Ministry of Finance model "Hubert" for variables and relationships characteristic for the circulation of alternative currencies. The simulated model is subject to the monetary policy shock, shocks into the tax rates and shock into the demand for the local currency. The variables in response to the monetary and fiscal policy shocks evolve similarly to the original version of the model.

The shock into the demand for the local currency displays a positive effect of the increase in membership for such money alternative on the economy. This outcome mimics the equations. The New Keynesian Phillips curve suggests relative inflationary tendencies for more demanded currency. By other words, individuals are willing to pay relatively more for goods denominated in a preferable currency. This fact reflects the reality where local currencies tend to be undervalued. Next, to convince employees to accept less preferable currency for their wages, employers must pay relatively higher wages. Altogether, the growth in demand for a currency has inflationary impact on prices while wages tend to shrink. Higher profit in the end motivates producers to boom production which positively affects economy.

While the production booms, the corresponding increase in the interest rate has negative effect on investment carried out in the national currency as illustrated by the model. The interest rate in the legal tender also affects the exchange rate. Subsequent appreciation of the currency results in the drop of net export. On the aggregate scale where the national economy consists of many local communities, the pressures on interest rate in the scenario with various local currencies in different localities might cancel out or be negligible as well as the consequent effect on the exchange rate.

The existence of local currencies signals to be valuable even without this presented localcurrency demand shock. The outline restrictive monetary policy shock for the national currency can have lower effect on a community as individual agents increase their demand for the currency alternative. Local community is then more resilient towards such exogenous shocks and due to the higher localization in such scenario.

In sum, emergence of an alternative currency could have a positive impact on the Czech product. The prices and demand for the legal tender might be though negatively affected by the growth of demand for the local currency such as the impulse-response functions proved. If the local currency circulates only in a small region and can thus barely affect the aggregate price level of the economy, one might view its circulation as favorable. The spread of the local currency should be further carefully examined. 


\section{Acknowledgements}

This work was supported by the University of Economics, Prague, Faculty of Informatics and Statistics in collaboration with the Faculty of Business Administration under the Grant IGA IG307026.

\section{References}

[1] Aliyev, I., Bobková, B. Štork, Z. 2014. Extended DSGE Model of the Czech Economy, Ministry of Finance of the Czech Republic, http://www.mfcr.cz/.

[2] Colacelli, M., Blackburn, D.J.H. 2009. Secondary Currency: An Empirical Analysis. Journal of Monetary Economics, vol. 56, iss. 3, pp. 295-308. doi:10.1016/j.jmoneco.2009.02.002.

[3] Dixit, A. K., Stiglitz, J.E. 1977. Monopolistic Competition and Optimum Product Diversity. The American Economic Review, vol. 67, iss. 3, pp. 297-308.

[4] Falagiarda, M., Marzo, M. 2012. A DSGE Model with Endogenous Term Structure. SSRN Scholarly Paper. Rochester, NY: Social Science Research Network. http://papers.ssrn.com/abstract $=2078094$.

[5] Gawthorpe, K. 2015. Impact of inflation rate on demand for alternative currency: case study for switzerland's wirtschaftsring. The 9th International Days of Statistics and Economics, Prague, http://apps.webofknowledge.com.zdroje.vse.cz/full_record.do?product=WOS\&search_mo $\mathrm{de}=$ GeneralSearch\&qid=23\&SID=W $1 \mathrm{ktrBertNAt14} \mathrm{cu} 2 \mathrm{ez} \&$ page $=1 \& \mathrm{doc}=1$.

[6] Gómez, G. M. 2010. What Was the Deal for the Participants of the Argentine Local Currency Systems, the Redes de Trueque? Environment and Planning A, vol. 42, iss. 7, pp. 1669-85. doi:10.1068/a42309.

[7] Jayaraman, R., Oak, M.. "Local Currency as a Development Strategy." Royal Economic Society Annual Conference 2002. Royal Economic Society, http://econpapers.repec.org/paper/ecjac2002/106.htm.

[8] North, P. 2007. Money and Liberation: The Micropolitics of Alternative Currency Movements. Minneapolis: University of Minnesota Press. ISBN 978-0816649631.

[9] Richey, S., Ikeda, K. 2009. Institutional Incentives and Trust: Marginalized Groups and the Creation of Trust in Local Government. Social Science Quarterly, vol. 90, iss. 4, pp. 911-26. doi:10.1111/j.1540-6237.2009.00669.x. 


\section{Appendix}

Figure 1: Monetary policy shock
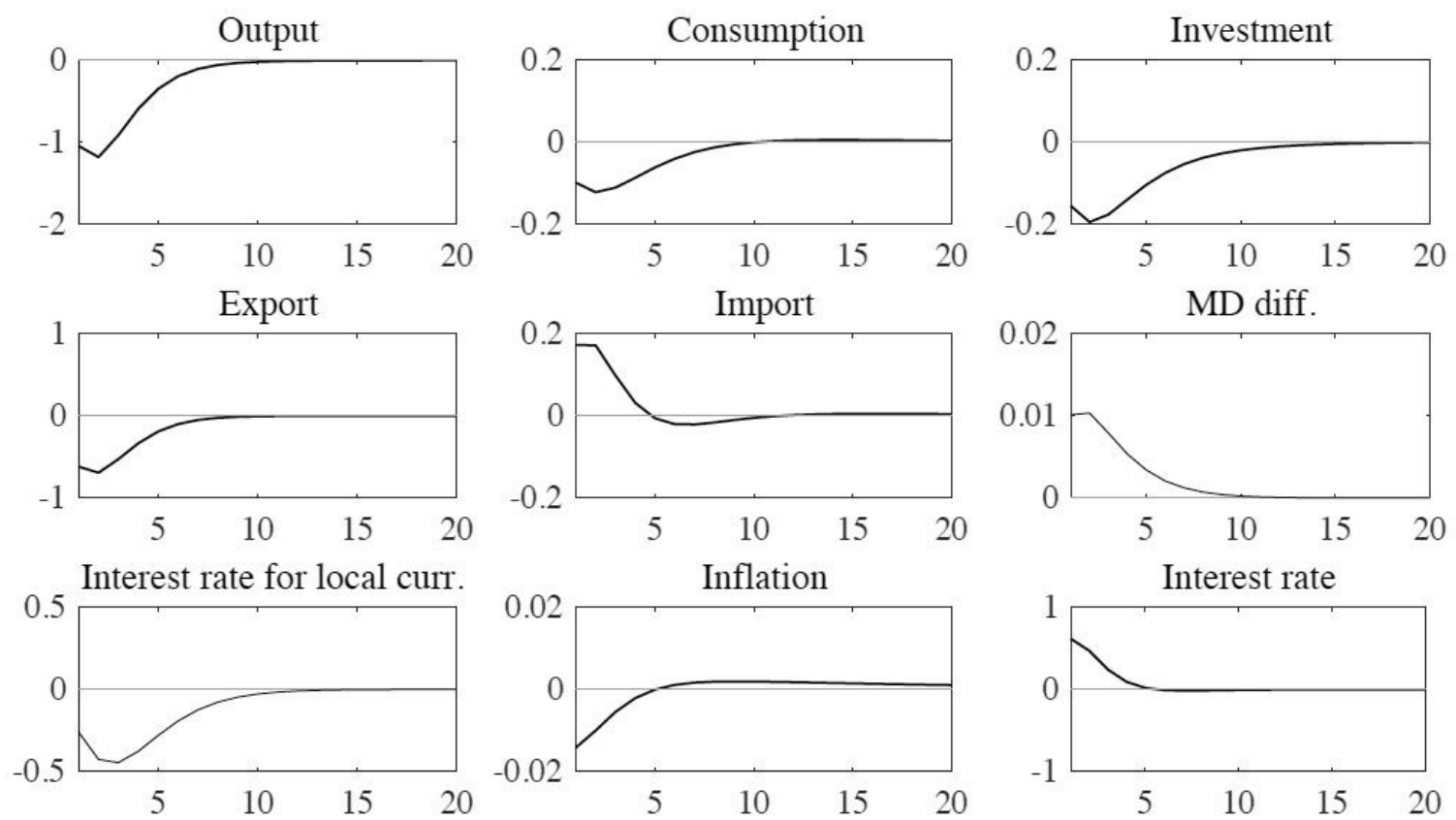

Source: Author's calculation. The horizontal line displays the number of simulated periods.

Figure 2: Shock into VAT tax
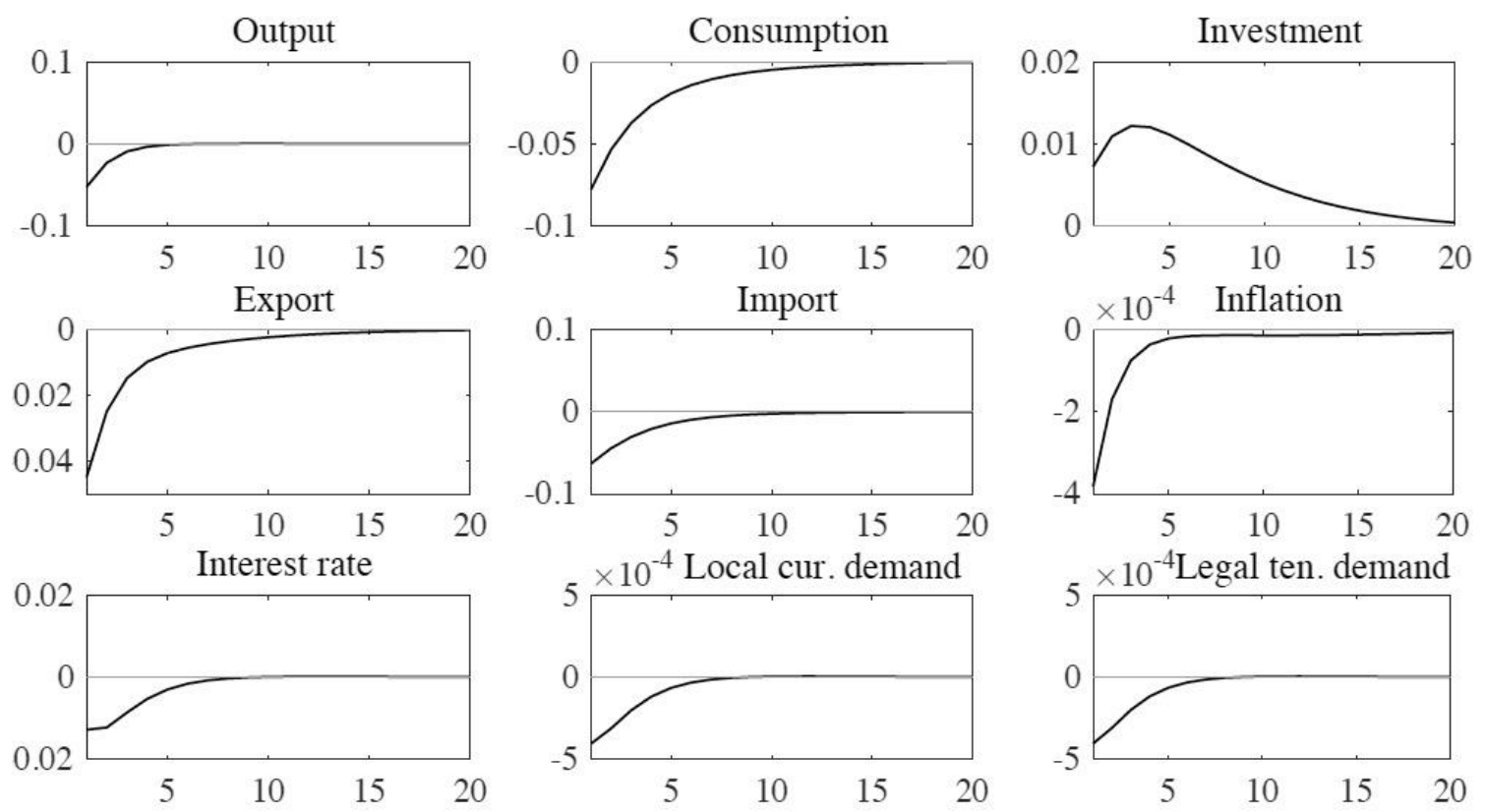

Source: Author's calculation. The horizontal line displays the number of simulated periods. 
Figure 3: Income tax shock
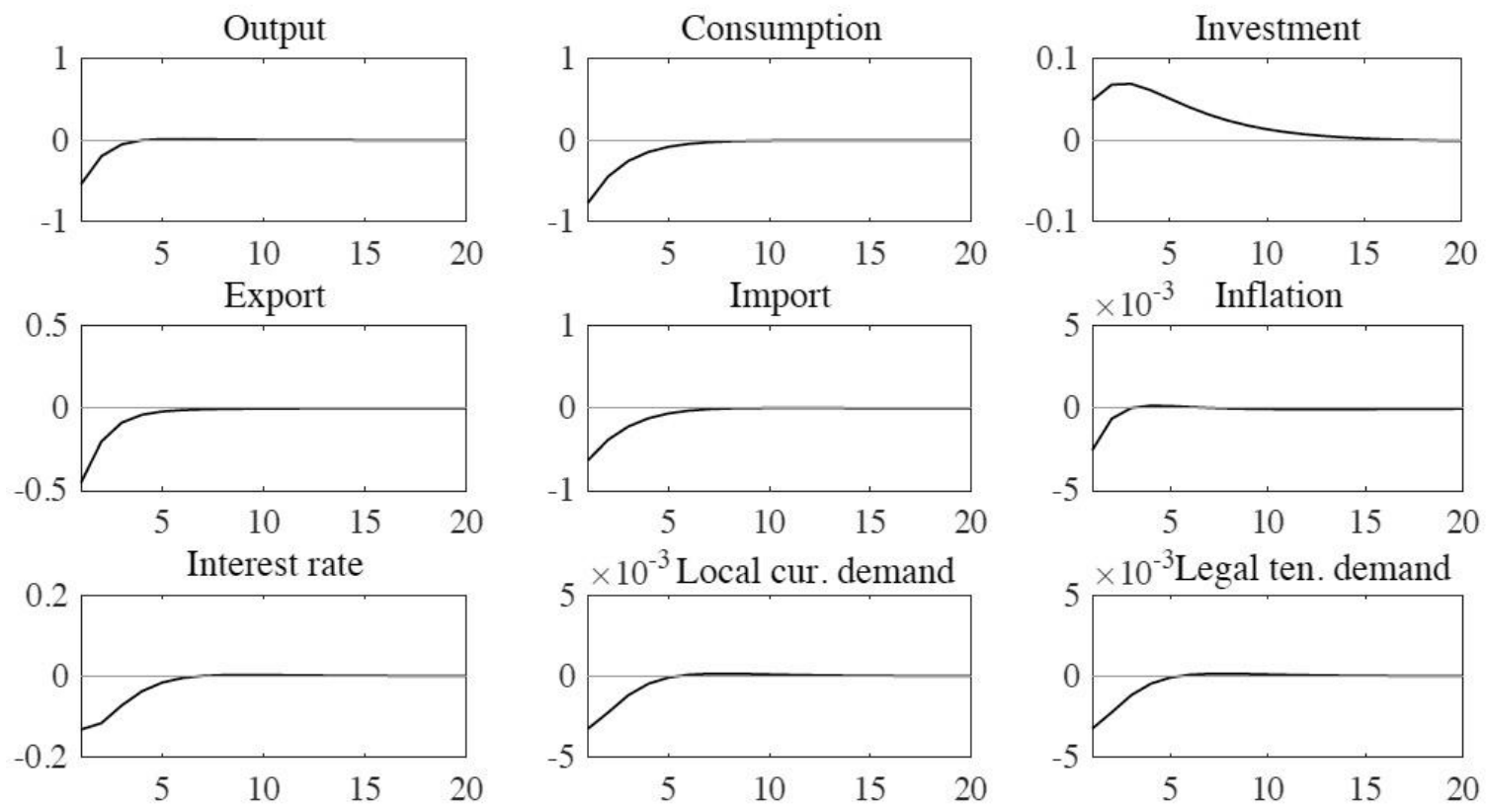

Source: Author's calculation. The horizontal line displays the number of simulated periods.

Figure 4: Shock into the demand for local currency:
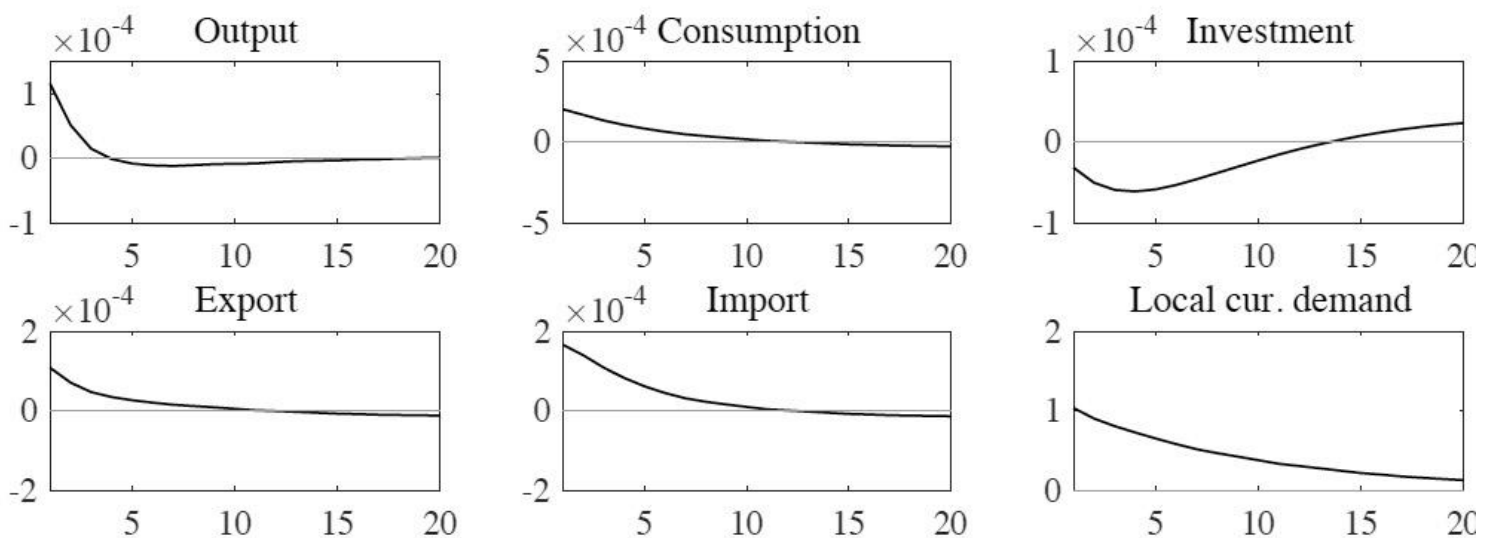

Local cur. demand

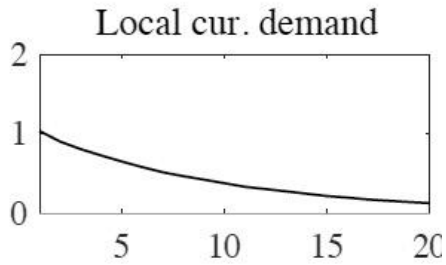

Legal ten. demand
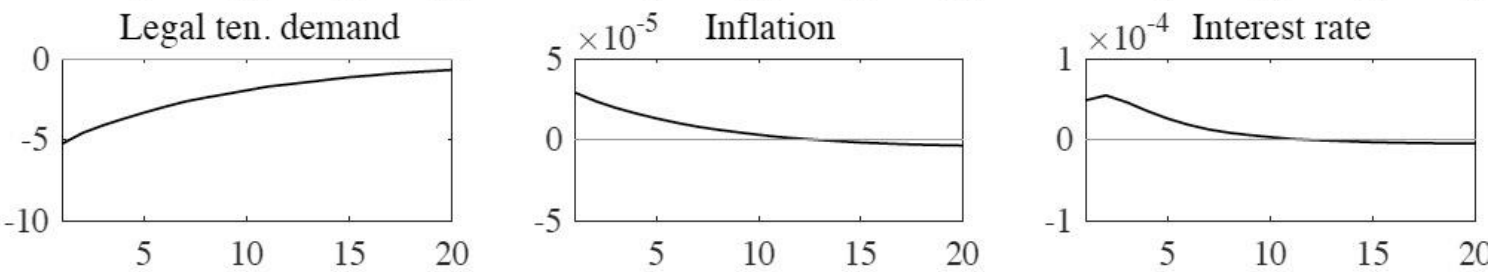

Source: Author's calculation. The horizontal line displays the number of simulated periods. 
20th International Scientific Conference AMSE

Applications of Mathematics and Statistics in Economics 2017

Szklarska Poręba, Poland 30 August 2017 - 3 September 2017

Table 1: Parameter estimates

\begin{tabular}{|c|l|c|c|c|c|c|c|}
\hline $\boldsymbol{\alpha}$ & 0.53 & $\boldsymbol{\theta}$ & 2 & $\boldsymbol{\omega}_{\boldsymbol{s i}}$ & 0.5 & $\lambda_{\boldsymbol{\pi}}$ & 1.5 \\
\hline $\boldsymbol{\beta}$ & 0.99 & $\boldsymbol{\theta}_{\boldsymbol{c}}$ & 0.3 & $\boldsymbol{\omega}_{\boldsymbol{s n \boldsymbol { x }}}$ & 0.25 & $\lambda_{\mathrm{y}}$ & 0.5 \\
\hline $\boldsymbol{\rho}_{\boldsymbol{p} *}$ & 0.5 & $\boldsymbol{\theta}_{\boldsymbol{c} *}$ & 0.3 & $\boldsymbol{\varepsilon}_{\boldsymbol{w}}$ & 0.2 & $\mathbf{s}_{\mathbf{x c}}$ & 0.7 \\
\hline $\boldsymbol{\rho}_{\boldsymbol{R}}$ & 0.52 & $\boldsymbol{\theta}_{\boldsymbol{i}}$ & 0.2 & $\mathbf{c}$ & 0.01 & $\mathbf{s}_{\mathbf{m c}}$ & 0.78 \\
\hline $\boldsymbol{\rho}_{\boldsymbol{t c}}$ & 0.6 & $\boldsymbol{\theta}_{\boldsymbol{i} *}$ & 0.2 & $\boldsymbol{s}_{\boldsymbol{d} \boldsymbol{s}}$ & 0.01 & $\boldsymbol{\omega}$ & 0.01 \\
\hline $\boldsymbol{\rho}_{\boldsymbol{t} \boldsymbol{k}}$ & 0.91 & $\boldsymbol{\theta}_{\boldsymbol{w}}$ & 2 & $\boldsymbol{\alpha}_{\boldsymbol{R}}$ & 0.32 & $\mathrm{U}$ & 0.01 \\
\hline $\boldsymbol{\rho}_{\boldsymbol{t r}}$ & 0.92 & $\kappa$ & 11 & $\boldsymbol{\delta}$ & 0.01 & $\psi^{\mathbf{N}}$ & 1.55 \\
\hline $\boldsymbol{\rho}_{\boldsymbol{t} \boldsymbol{w}}$ & 0.61 & $\boldsymbol{\mu}_{\boldsymbol{c m}}$ & 0.22 & $\boldsymbol{\mu}_{\boldsymbol{i m}}$ & 0.32 & $\boldsymbol{\omega}_{\mathbf{s s}}$ & 0.5 \\
\hline $\boldsymbol{\rho}_{\boldsymbol{u} \boldsymbol{z}}$ & 1 & $\boldsymbol{\rho}$ & 0.9 & $\boldsymbol{s}_{\boldsymbol{R}}$ & 1.55 & $\boldsymbol{\phi}_{\mathbf{R}}$ & 0.52 \\
\hline $\boldsymbol{\rho}_{\boldsymbol{v}}$ & 0.5 & $\boldsymbol{\rho}_{\boldsymbol{l}}$ & 0.9 & $\boldsymbol{u}_{\boldsymbol{z}}$ & 1.005 & $\boldsymbol{\alpha}_{\boldsymbol{R}}$ & 0.32 \\
\hline $\boldsymbol{\rho}_{\boldsymbol{t}}$ & 0.9 & $\boldsymbol{\varepsilon}_{\boldsymbol{p}}$ & 0.2 & $\boldsymbol{h}_{\boldsymbol{r}}$ & 0.8 & & \\
\hline
\end{tabular}

Source: Author's calculation along with Aliyev et al. (2014). 